\title{
Ortner's syndrome as the first symptom of thoracic aortic aneurysm, with coexisting infrarenal abdominal aortic aneurysm and critical stenosis of the left internal carotid artery
}

Zespół Ortnera jako pierwszy objaw tętniaka aorty piersiowej, ze współistniejącym podnerkowym tętniakiem aorty brzusznej i krytycznym zwężeniem tętnicy szyjnej wewnętrznej lewej

\author{
Sławomir Wojczyk', Janusz Kuśmierz', Marta Szwengruben', Rajmund Ratman', Józefa Dąbek² \\ 'Regional Specialised Hospital No. 4 in Bytom, Bytom, Poland \\ 2Department of Cardiology, School of Health Sciences in Katowice, Medical University of Silesia in Katowice, Katowice, Poland
}

Abstract

\begin{abstract}
Ortner's syndrome is a non-specific symptom of thoracic aortic aneurysm, therefore, it constitutes a challenge - both, diagnostic and therapeutical - for contemporary physicians.

This paper presents the case of a 70-year-old patient reporting a hoarse voice for several months. Due to the suspicion of neoplastic disease, the diagnostics were deepened and during this diagnostic, an aneurysm of the descending thoracic aorta with the concurrent infrarenal abdominal aortic aneurysm and critical stenosis of the left internal carotid artery was diagnosed. Based on the clinical condition and the imaging examinations, the patient was qualified for endovascular surgical treatment - the implantation of stent grafts into the thoracic aorta and the abdominal aorta, preceded by the endarterectomy of the left internal carotid artery and one of the variants of debranching of the aortic arch.
\end{abstract}

Key words: thoracic aortic aneurysm, abdominal aortic aneurysm, Ortner's syndrome, endovascular stent-graft procedure, debranching technique

\section{Introduction}

A thoracic aortic aneurysm is a disease occurring with a frequency of about 5.6/100,000 patients/year [1]. Its main causes are atherosclerotic degeneration, cystic medial degeneration, aortic dissection, congenital diseases of the aorta and past injuries or surgeries of the aorta [2]. The course of thoracic aortic aneurysm is most frequently asymptomatic, and the disease is diagnosed in imaging examinations performed due to other reasons [3]. The symptoms which may suggest the occurrence of thoracic aortic aneurysm include chest or back pain as well as hoarse voice associated with the pressure exerted by the aneurysm on the left recurrent laryngeal nerve, which is referred to as Ortner's syndrome [4]. This article will present the case of a patient with a thoracic aortic aneurysm manifesting itself precisely through this non-specific syndrome.

\section{Case report}

In July 2019 the 70 -year-old patient made an appointment with a general practitioner due to hoarse voice persisting for 2 months. The patient had been a ciga- 


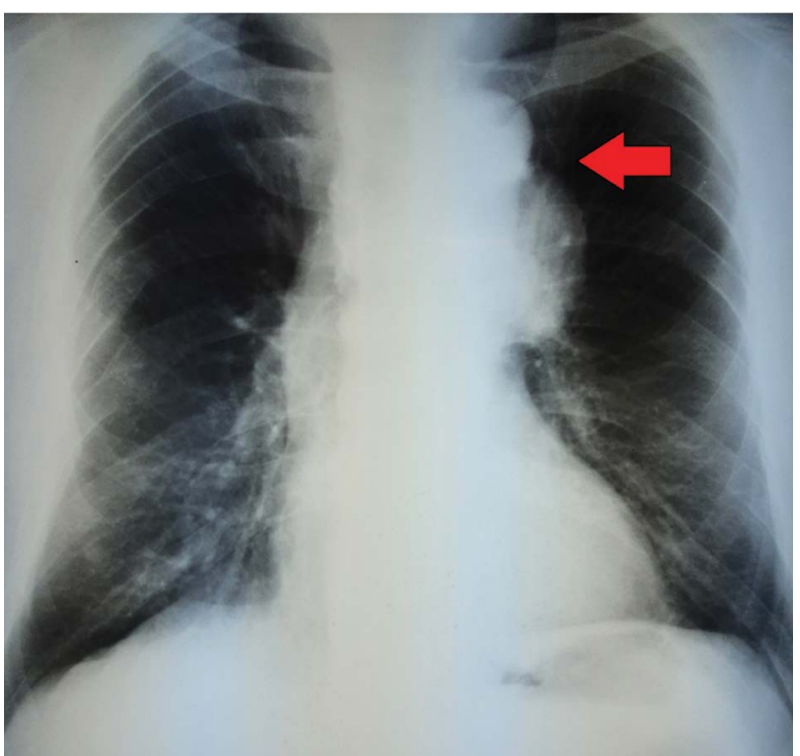

Figure 1. The chest $\mathrm{X}$-ray in which opacity was indicated in the area of the left lung hilum

rette smoker for several dozen years and he had been treated due to arterial hypertension. Within the scope of basic outpatient diagnostics, the patient had a chest $X$-ray taken, which demonstrated opacity in the area of the left lung hilum (Fig. 1). Due to the above, the patient was referred to the Pulmonology Department. The performed chest CT excluded proliferative lesions, whereas it revealed a saccular aneurism of the descending thoracic aorta, of a maximum diameter of $6 \mathrm{~cm}$, located in the area of the origin of the left subclavian artery. The performed ultrasound examination demonstrated also a infrarenal abdominal aortic aneurysm of a maximum diameter of about $7 \mathrm{~cm}$.

Based on the above results, the decision was made to admit the patient to the Department of Vascular Surgery in Bytom (5 August 2019). During the history-taking conducted upon the hospital admission, the patient reported that he had experienced a blunt injury of the thorax over a dozen years before. The physical examination demonstrated the occurrence of a hoarse voice and palpable pulsing resistance in the middle abdomen. The conducted angiography $\mathrm{CT}$ of the thoracic and abdominal aorta demonstrated a saccular aneurysm of the descending thoracic aorta of the following dimensions: $62 \times 60 \mathrm{~mm}$ (Fig. 2) and an abdominal aortic aneurysm of the following dimensions: $76 \times 79 \mathrm{~mm}$ (Fig. 3).

Due to the presence of a hoarse voice, a laryngoscopy was conducted, which demonstrated complete paralysis of the left vocal cord. Moreover, a Colour Doppler ultrasound examination of the carotid arteries was performed, which demonstrated also critical stenosis of the left internal carotid artery. The echocardiography examination, performed as part of the cardiological consultation, demonstrated an LVEF of $60 \%$. According to the assessment of a cardiologist, a surgical procedure was burdened with a moderate risk of cardiovascular complications. Based

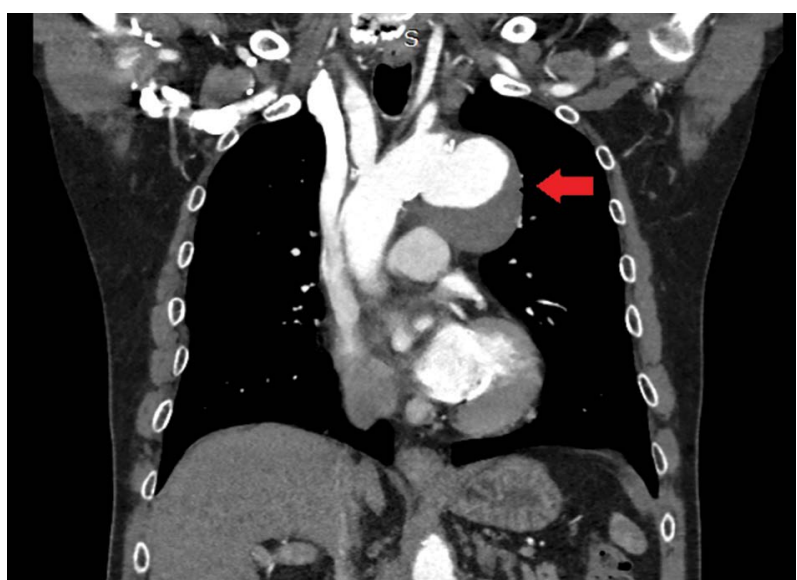

Figure 2. Angiography CT of the thoracic aorta with the visible saccular aneurysm of the descending thoracic aorta of the following dimensions: $62 \times 60 \mathrm{~mm}$

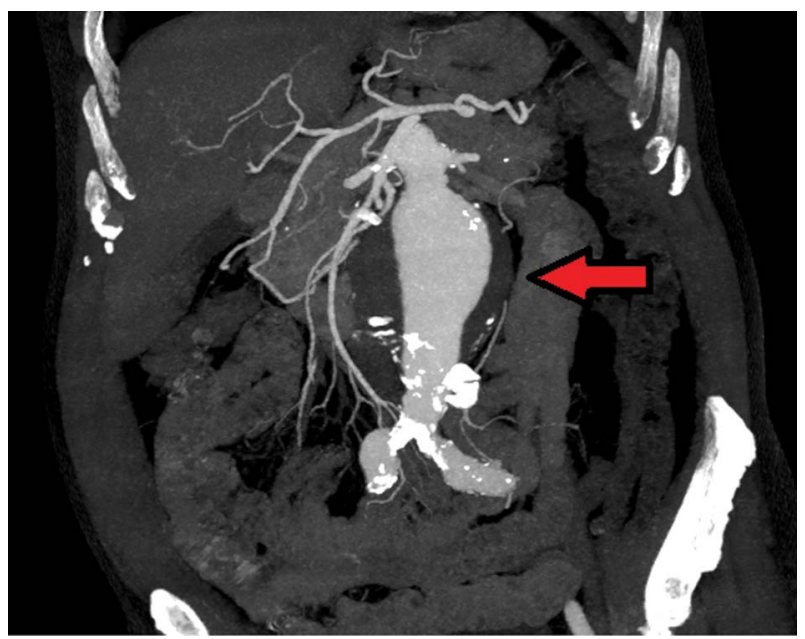

Figure 3. Angiography CT of the abdominal aorta with the visible abdominal aortic aneurysm of the following dimensions: $76 \times 79 \mathrm{~mm}$

on the above results, the patient was first qualified for the surgical treatment of the left internal carotid artery.

On 12 August 2019, in regional anaesthesia of the cervical plexus, the patient underwent endarterectomy of the left common, internal and external carotid arteries with the reconstruction of the artery with a simple continuous suture technique. No complications occurred in the postoperative period. On the 3rd day after the surgery, the patient was discharged home in good general and local condition.

On 13 September 2019, the patient was once again admitted to the Vascular Surgery Department in Bytom to implant a stent graft to the thoracic aorta. In the first stage, the debranching technique was applied by performing the carotid-carotid bypass grafting procedure from the right common carotid artery to the left common carotid artery using the PTFE Ring 6 prosthesis and carotid-subclavian by-pass grafting from the left common carotid artery to 


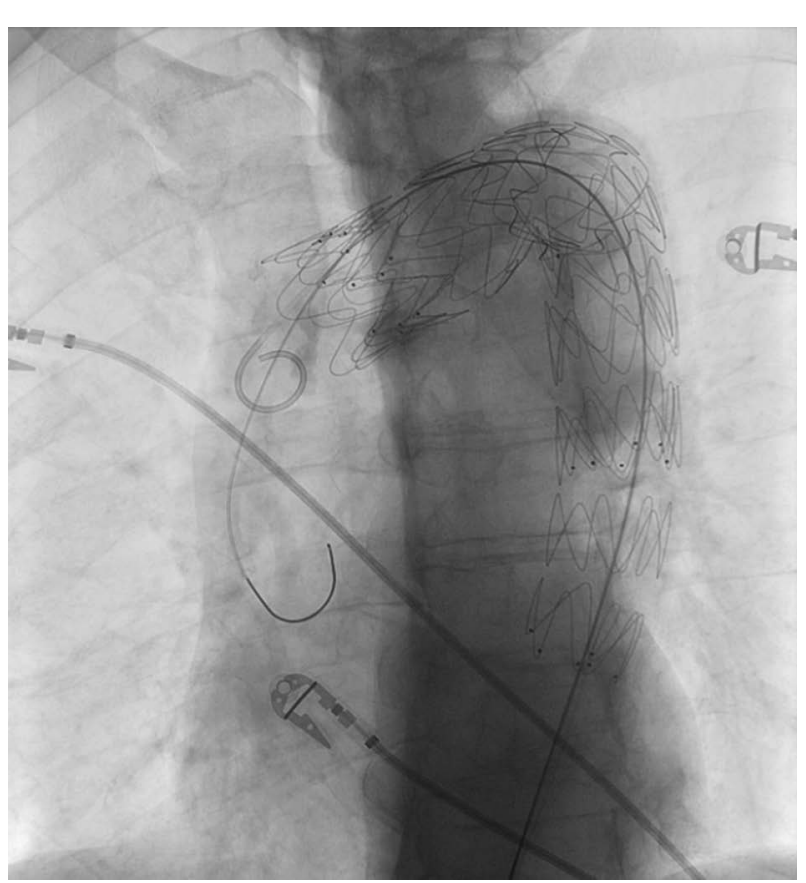

Figure 4. The reimplantation of the second stent graft of the thoracic aorta; the stent graft was positioned proximally in reference to the first one, at the ostium of the brachiocephalic artery

the left subclavian artery using the PTFE Ring 6 prosthesis, with the ligation of the left common carotid artery. No complications occurred in the perioperative period. After the surgery the pulse at the radial arteries was symmetrical. However, persisting difference in arterial blood pressure by about $40 \mathrm{~mm} \mathrm{Hg}$ was observed between the right and the left upper extremity.

After 6 days the patient underwent the procedure of implanting the Zenith Cook Alpha stent graft to the thoracic aorta right behind the origin of the brachiocephalic artery with covering the stump of the left common carotid artery and the left subclavian artery. The performed check-up aortography demonstrated a type IA endoleak to the aneurysm sac. Due to the above, the reimplantation of the second stent graft was performed - this stent graft was positioned proximally about the first one, at the ostium of the brachiocephalic artery (Fig. 4). The check-up aortography did not show the features of an endoleak to the aneurysm sac, with the maintained appropriate blood flow through the brachiocephalic artery and the carotid arteries, carotid-carotid bypass graft and the carotid-subclavian left-sided bypass graft.

On 28 October 2019, the patient was admitted for the last stage of treatment at the Department of Vascular Surgery. That was the time when the Zenith Alpha stent graft to the abdominal aorta and the common iliac arteries was implanted (Fig. 5). During the procedure, the aortography of the thoracic aorta was performed, demonstrating the properly positioned thoracic stentgraft, without features of an endoleak to the aneurysm

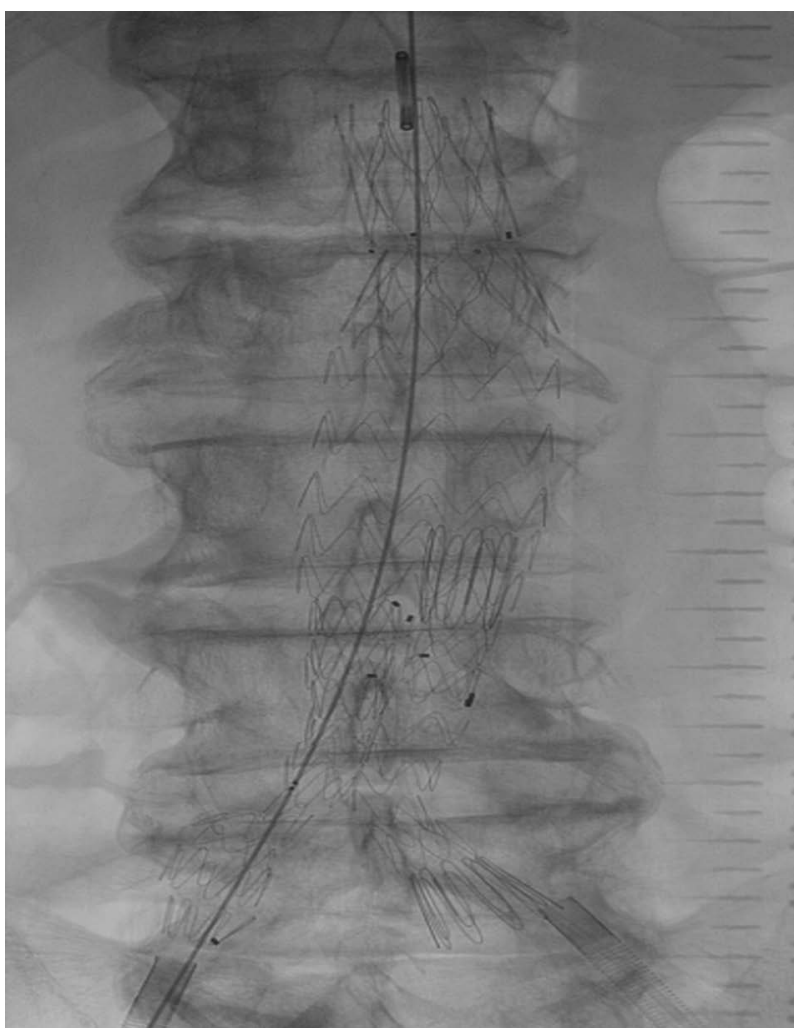

Figure 5. The procedure of implanting the Zenith Alpha stent graft to the abdominal aorta and the common iliac arteries

sac. There were no complications in the postoperative period and the patient was discharged home on the $3 \mathrm{rd}$ day after the surgery.

After a month from the surgery, a check-up angiography CT examination was performed which confirmed the proper positioning of the implanted stent grafts (Fig. 6 and Fig. 7), without features of endoleaks and with maintained blood flow in the carotid-carotid bypass graft and the carotid-subclavian bypass graft. The Colour Doppler ultrasound examination demonstrated the proper blood flow in the left internal carotid artery without features of restenosis. Currently, the patient is under constant outpatient control, he demonstrates almost complete cessation of a hoarse voice and he has returned to full fitness.

\section{Discussion}

The complexity of the presented case demonstrates the great importance of holistic diagnostics and planning the treatment individually for each patient. At the Department of Vascular Surgery in Bytom, the standard procedure in the case of every patient with the thoracic aortic aneurysm and/or abdominal aortic aneurysm is deepening the diagnostics by the Colour Doppler ultrasound examination of the carotid arteries. It is because the concurrence of an aortic aneurysm with the steno- 


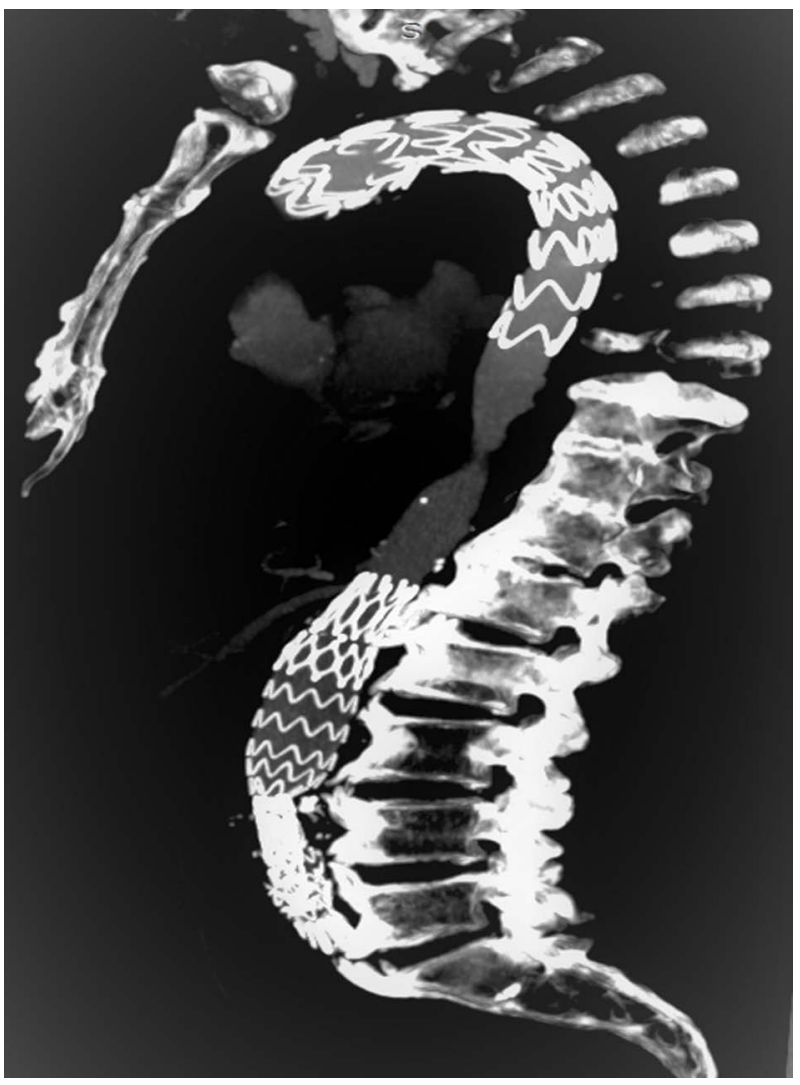

Figure 6. The check-up computed tomography angiography examination confirms the proper positioning of the implanted stent grafts of the thoracic aorta and the abdominal aorta as well as of the common iliac arteries

sis of carotid arteries significantly increases the risk of perioperative brain stroke. In every case, it forces us to consider the order of the performed operations. In the presented case, due to the concurrence of critical stenosis of the left internal carotid artery, the decision was made to perform the endarterectomy of the carotid artery in the first place. Moreover, in case of the occurrence of an aortic aneurysm that embraces the aortic arch and/or the initial section of the descending aorta, it is sometimes necessary to apply the debranching technique, i.e., the removal of the branches of the aortic arch through forming extra-anatomic by-passes depending on the positioning and the morphology of the aneurysm. In the above case where, based on the performed sizing, the proximal landing zone of the stent-graft was planned to place in zone 1 (i.e., between the origin of the brachiocephalic artery and the left common carotid artery), it was necessary to apply the variant of debranching in the form of carotidcarotid bypass grafting and carotid-subclavian left-sided by-pass grafting [5].

The presented case is even more interesting because the only symptom which was the reason for deepening the diagnostics was a hoarse voice caused by the paralysis of the recurrent laryngeal nerve pressed by the thoracic aortic aneurysm. This symptom was for the first

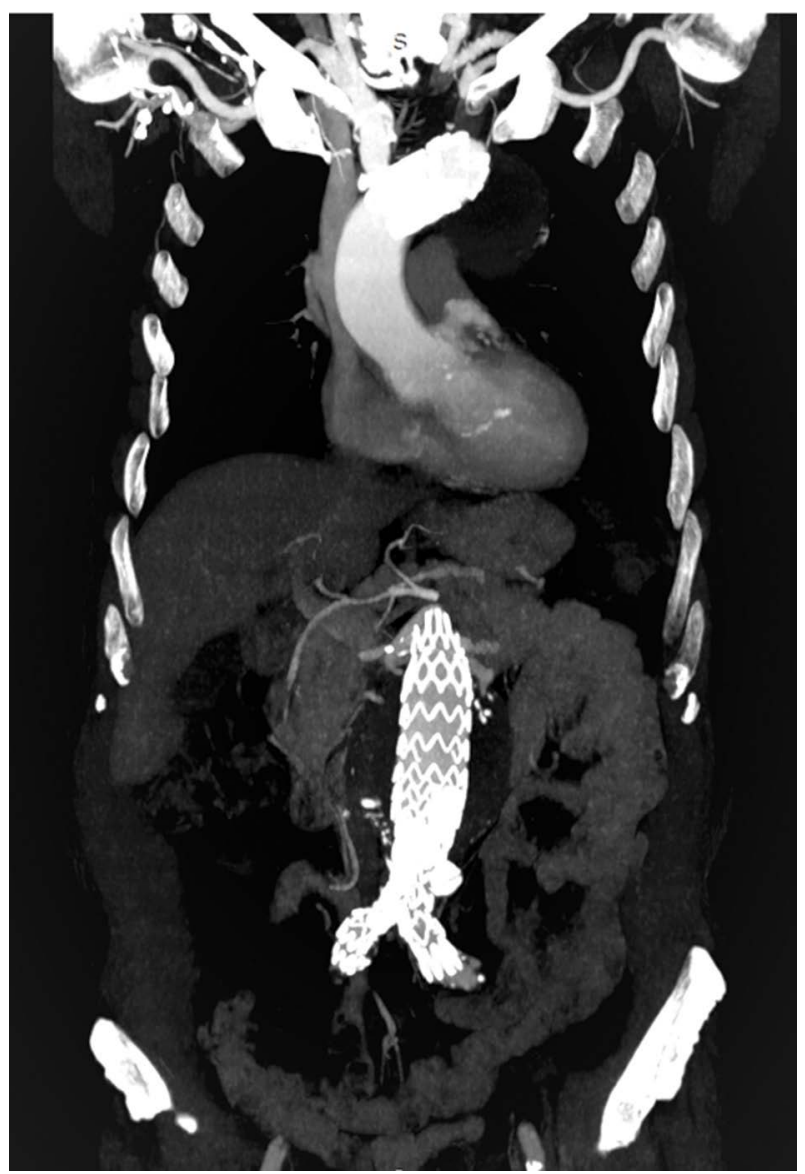

Figure 7. The check-up computed tomography angiography examination confirmed the proper positioning of the implanted stent grafts

time described in the literature by an Austrian physician, Norbert Ortner, in the year 1897. In Ortner's syndrome, the paralysis of the laryngeal nerve occurs most frequently as a result of the pressure of the enlarged left atrium caused by the mitral valve stenosis, and less frequently due to other reasons such as aortic arch aneurysm, thoracic aortic aneurysm or an aneurysm of pulmonary arteries, pulmonary hypertension and aberrant subclavian artery [4].

The presented case demonstrates that an element which is hugely important in the practice of a vascular surgeon is not only the correct diagnosing of vascular disease, the precise planning of the stages of surgical treatment and carrying it out properly but also a comprehensive approach to the patients, to all of their symptoms and comorbidities.

\section{References}

1. Melton LJ, Bickerstaff LK, Hollier LH, et al. Thoracic aortic aneurysms: a population-based study. Surgery. 1982; 92(6): 1103-1108, indexed in Pubmed: 7147188.

2. Salameh MJ, Black JH, Ratchford EV. Thoracic aortic aneurysm. Vasc Med. 2018; 23(6): 573-578, doi: 10.1177/1358863X18807760, indexed in Pubmed: 30370834. 
3. Saeyeldin AA, Velasquez CA, Mahmood SU, et al. Thoracic aortic aneurysm: unlocking the "silent killer" secrets. Gen Thorac Cardiovasc Surg. 2019; 67(1): 1-11, doi: 10.1007/s11748-017-0874-x, indexed in Pubmed: 29204794.

4. Subramaniam V, Herle A, Mohammed N, et al. Ortner's syndrome: case series and literature review. Braz J Otorhinolaryngol. 2011;
77(5): 559-562, doi: 10.1590/s1808-86942011000500004, indexed in Pubmed: 22030961.

5. Alonso Pérez M, Llaneza Coto JM, Del Castro Madrazo JA, et al. Debranching aortic surgery. J Thorac Dis. 2017; 9(Suppl 6): S465-S477, doi: 10.21037/jtd.2017.03.87, indexed in Pubmed: 28616343.

\section{Address for correspondence:}

Lek. Sławomir Wojczyk

Regional Specialised Hospital №. 4 in Bytom,

10 Aleja Legionów Street, 41-902 Bytom, Poland

e-mail: slawoj1@vp.pl

Praca wpłynęła do Redakcii: 23.12.2020 r. 